$\mathrm{Y} \triangle \mathrm{K} \mathrm{K} 659.4$

ББК 60.842

DOI 10.22394/1682-2358-2017-5-123-131

E.B. Kboroltseva, Candidate of Sciences (Philosophy), Docent at the Social Communications Department, Povolzhsky Institute of Management named after P.A. Stolypin, Branch of the Russian Presidential Academy of National Economy and Public Administration

A.V. Fedorova, Candidate of Sciences (Philosophy), Docent at the Social Communications Department, Povolzhsky Institute of Manasement named after P.A. Stolypin, Branch of the Russian Presidential Academy of National Economy and Public Administration

\section{MODERN FRAMES OF PUBLIC RELATIONS IN CRISIS SITUATIONS}

The article analyzes the complex context of modernity, which includes social, organizational and managerial risks, conflicts, small horizons of forecasting and planning, crisis and catastrophic communications. The authors consider several levels of generalization of public relations in crisis situations: socio-philosophical, sociological and methodological. They investigate the problems of improving the management of crisis communications using frames.

Key words and word-combinations: frame, modernity, crisis, management, public relations, frame analysis.
E.Б. ХорольцеВа, кандидат философских наук, дочент кафедрь сочиальньгх коммуникаиий Поволжского института упраљления имени П.А. Стольтина - филиала Россииской академии народного хозяйства и государственной службь при Президенте РФ (email: borolceva-e@mail.ru)

A.В. Федороља, кандидат философских наук, доцент кафедро социальньх коммуникаций Поволжского института упраһления имени П.А. Стольпина - филиала Российской академии народного хозяйства и государственной службь при Президенте РФ (email: anna_fedorova_76@list.ru)

\section{COBPEMEHНЫЕ ФРЕЙМЫ СВЯЗЕЙ С ОБЩЕСТВЕННОСТЬЮ В КРИЗИСНЫХ СИТУАЦИЯХ}

Аннотация. Анализируется сложный контекст современности, включающий социальные и организационно-управленческие риски, конфликты, малые горизонты прогнозирования и планирования, кризисные и катастрофичные коммуникации. Авторы рассматривают несколько уровней генерализации связей с общественностью в кризисных ситуациях: социально-философский, социологический и методологический. Исследуются проблемы совершенствования управления кризисными коммуникациями с помощью фреймов.

Ключевые слова и словосочетания: фрейм, современность, кризис, управление, связи с общественностью, фрейм-анализ.

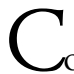

овременность характеризуется кризисными проявлениями в политическом, социальном, экономическом, культурном и организационном поле. Они представця- 
ют определенные труАности дмя понимания и исследовательской рефлексии. САожный контекст современной ситуации определяется высокими рисками, которыми труАно, а порой и невозможно управмять. Высокий уровень конфциктогенности соџиацьных практик акторов обусловлен, на наш взгляА, косностью в использовании стратегий управления конфликтами или необразованностью и необученностью.

Аругие особенности современности взаимосвязаны со сложностью социальных практик (особенно коммуникационных), нелинейностью их развития и непропорџиональностью затрачиваемых усиций и получаемых результатов. Сложность можно объяснить многообразием коммуникаций, слабой рефмексией по отношению к ним, непроработанностью новых направлений и поАходов к изучению коммуникационных взаимодействий и связанных с ними фреймов. Аругим аспектом сложности коммуникаџионных практик явцяются малые горизонты прогнозирования и планирования и слабый контроль со стороны современных управленцев.

Эти специфические черты современности - необходимые фрейми амя эффективного управления и могут быть Аополнены временно́й компрессией и высокой неопределенностью, сосредоточенностью рутинизированных и инновационных практик в настоящем (характеристики темпорахьности), культурологичским фреймом и фреймами социальных, организационно-управменческих, рефлексивных и коммуникаџионных практик. Фреймирование позволяет осуществить «поворот к практике», повседневным коммуникациям, управцять ими и своевременно совершенствовать $[1 ; 2]$. Фреймирование это стремление исследователей произвести рефокусиробку на кризисных коммуникациях в современной ситуации.

Обратимся к историческим преАпосылкам теории фреймов. Теорию фрейманализа разработал И. Гофман. Он перенес метафору фрейма и идею транспарентности из сферы кинематографа, в которой активно и увлеченно работал, в сферу исследовательских вопросов соџиологического знания. В настоящем существует Ава понимания фрейма: мингвистическое (фрейм - это «иерархическая система знаний об обозначаемом») и социологическое (фрейм как «структурный контекст повседневного взаимодействия»). В последнем случае мы сталкиваемся с психологической интерпретацией фрейма (Г. Бейтсон) и соџиологической, подробно разработанной И. Гофманом и В.С. Вахштайном.

С позиций соџиологического знания фреймы обладают следующими основополагающими характеристиками: они представцяют собой схемы репрезентации практик повсеАневной реальности; могут объединяться в системы фреймов и фреймы фреймов, то есть выстраивать метаконтексты; вбирают в себя дискретные практики акторов, участвующих во взаимодействиях; явцяются метакоммуникативным образованием - сообщением о сообщении; настолько реальны, насколько могут распознаваться участниками соџиальных ики коммуникационных взаимодействий или рефмексирующими субъектами (анацитиками, экспертами, управценцами).

Встает вопрос, затрагивающий граниџы самого фрейма, возникает рефлексивное сомнение в правомерности использования фрейм-анализа в качестве 
современной технологии управления связями с общественностью в кризисных ситуациях. В.С. Вахштайн отмечает: «Исконной сферой теории фреймов остаются порядки взаимодействий в публичных местах, наблюдаемые цепочки коммуникаџий миџом к мицу - “реальные”, “Аействительные”, повторяющиеся повседневные действия мюдей» [2, с. 256]. Рутинизированные практики проявляют себя в ситуации соџиальных, организационно-управленческих и коммуникационных взаимодействий. Метафреймом по отношению к связям с общественностью в кризисных ситуащиях выступает современность.

Остается дискуссионным вопрос, затрагивающий инвариантные и уникальные характеристики современности. Какие феномены могут быть отнесены к современности как некоему состоянию общества, коммуникаций и организационно-управленческих практик? Выделим следующие подходы, позволяющие ответить на этот вопрос. ОАин из них - ситуационный, раскрывающий сложные и разнообразные характеристики современности через понятие ситуации на различных уровнях ее осмысления (соџиальном, коммуникационном и организационно-управленческом). Обращение к понятию «ситуации», «соџиальной ситуации» особенностям описания процессов восприятия соџиальной ситуации традиционно происходит с позиций психологического подхода. Психологические исследования обращаются к анализу ситуативных факторов (рис. 1). Они выделяют значимые условия и факторы, которые оказывают влияние на поведение человека (например, бихевиоризм). Затрагивают они и разнообразные интерпретации социальной ситуации, в которой находится чемовек.

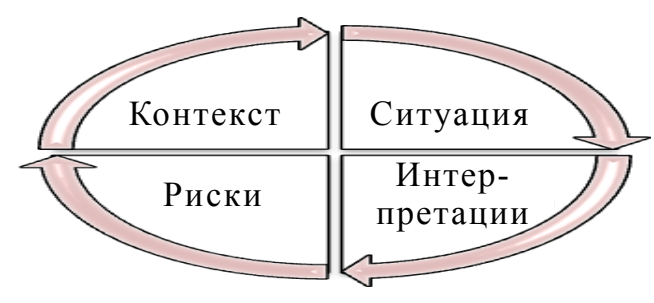

Рис. 1. Ситуационные факторы современности

Существует три основных подхода, которые способствуют изучению соџиальных ситуаций и поведения человека. Эти подходы созвучны исследованиям И. Гофмана ими его изображениям повседневной реальности (например, когда он описывал игру детей в песочниџе, наблюдая за ними из окна): основные значимые характеристики ситуации задаются извне (по отношению к человеку) и исследуется реальное поведение человека по отношению к ним. При этом мы сталкиваемся с рисками разнообразных контекстов как участников, так и экспериментаторов; слиянием наблюдателя и изучаемой ситуации.

Актор остается погруженным в ту или иную соџиальную ситуаџию и описывает свой опыт «проживания этой ситуащиц». При этом возникают риски объективности и надежности предоставленных описаний, риски наложения коммуникационных контекстов, и встает вопрос о том, насколько можно доверять подобным описаниям с научной точки зрения, что считать данными 
дмя проводимых исследований. Некая домя субъективизма может быть устранена благодаря совместным обсуждениям размичных интерпретаций.

Изучение акторов в «естественных условиях». При этом возникают риски корректности используемых методов изучения ситуационных переменных и установления различных корремяџионных характеристик поведения акторов. Методологическая неясность может быть дополнена слабым использованием праксиографических методов, методов нарративного анализа и описания, фрейм-анализа [3] .

Американские соџиологи-ситуационисты У. Томас и Ф. Знанеџкий, на чьи труды опирается соџиальная психология, опредемяют ситуаџию как совокупность установок и ценностей, которыми руководствуется как отдельный актор, так и целая группа в проџессе деятельности, а также в процессе планирования и оџенки деятельности. Он выделяет структурно-темпоральные характеристики ситуации в зависимости от уровней активности акторов.

Различные уровни генерализации позволяют выделить объективные условия, которые оказывают давление на актора ици группу. К ним можно отнести экономические, соџиальные, политические, религиозные и интемлектуальные ценности. При этом возникают риски согласования установленных объективных норм и ценностей с нормами и правиками текущей деятельности.

Следующий уровень представлен установками акторов или группы, которые опредемяют активность в разворачивающейся ситуации в настоящем. При этом возникают риски следования установленным нормам и правилам или риски нарушения установленных норм и ценностей в случае неудобности их Аля исполнения, когАа они перестают выполнять функцию регуляторов поведения.

На последнем уровне осуществляется определение соџиальной ситуации через типизацию установок и ценностей и расстановку приоритетов среди них. При этом имеют место риски рассогласования разнообразных активностей кичности (одна установка может детерминировать множество форм поведения), а также риски системного упорядочивания установок или ценностей, когда одна установка или ценность подчиняет себе, упорядочивает остальные.

В процессе определения социальной ситуации мы не можем пренебрегать смыслами, которыми человек наделяет предметы и объекты повседневной реальности. Возникает новый фрейм коммуникационного характера, когда мы сообщаем о сообщаемом. Символический и рефмексивный контекст, сопровождающий проџесс формирования индивидуального опыта, помогает не только реагировать на значения ситуации в настоящем, но и понимать смысмы, контексты и значения прошлого, пробрасывать цели и задачи в будущее, согласовывать временные модусы. Особую значимость приобретает быстрота перехода из повседневного опыта в рефмексивный контекст [4].

Благодаря трудам К. Аевина возникает понимание закона (функциональные характеристики элементов конкретного события или ситуаџии) как важной составцяющей конструктивного представления ситуаџии [5; 6]. Проџесс конструктивного представления ситуаџии предполагает, чтобы событие выводимось из ситуации, то есть причину того или иного события необходимо находить в отношениях между событием (объектом) и ситуацией. К. Аевин 
вводит понятие «поле», под которым понимает совокупность контингентных взаимосвязей объективных и субъективных факторов, оказывающих вмияние на поведение человека. Поле содержит конкретные характеристики (цели, потребности, мечты, страхи, соџиальные связи) и общие характеристики (атмосфера напряженности, враждебности, Аоверия или дружелюбия, а также свобода воли) (рис. 2).

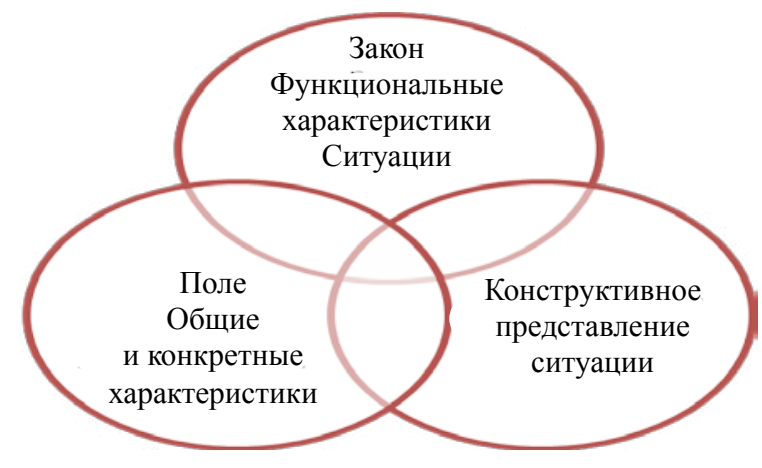

Рис. 2. Коннотаџии соџиальной ситуаџии

Важным методологическим основанием теории поля К. Аевина становится различение ситуации и жизненного психологического пространства. Человек может быть вовлечен во множество ситуаџий, он стоит на пересечении разцичных многообразных и сложных ситуаций, что в современном понимании явцяется ситуацией неопределенности и риска. Жизненное психологическое пространство аккумулирует значимые факторы и условия, выступающие обстоятельствами, которые определяют поведение человека [6, с. 263].

Фреймы современной ситуаџии и методологические фреймы дополняются фреймом кризисной ситуаиии. Ее отличают следующие признаки: продолжительный характер - кризисная ситуация бнезапно наступает и Аолго существуют по времени; кумулятивный эффект, связанный с послеАствиями кризисной ситуаций (рис. 3). Воздействие, оказываемое кризисными ситуациями, может многократно усициваться благодаря соџиальному, коммуникационному, управценческому и организационному контекстам; кризисные ситуации нарушают привычный порядок, рутинизированные и опривыченные практики разрывают коммуникационые контексты, требуют повышенного внимания и новых адаптивных способностей по управлению и преодомению ими.

Коммуникаџионый контекст связей с общественностью находится в когнитивных отношениях с характеристиками кризисных ситуаций и опредемяется как практики самопредъявления, направленные на подлержание репутации, имиджа и согласованных внутренних и внешних коммуникаций по отношению к целевым аудиториям. Это следующий современный фрейм связей с общественностью в кризисных ситуациях. 


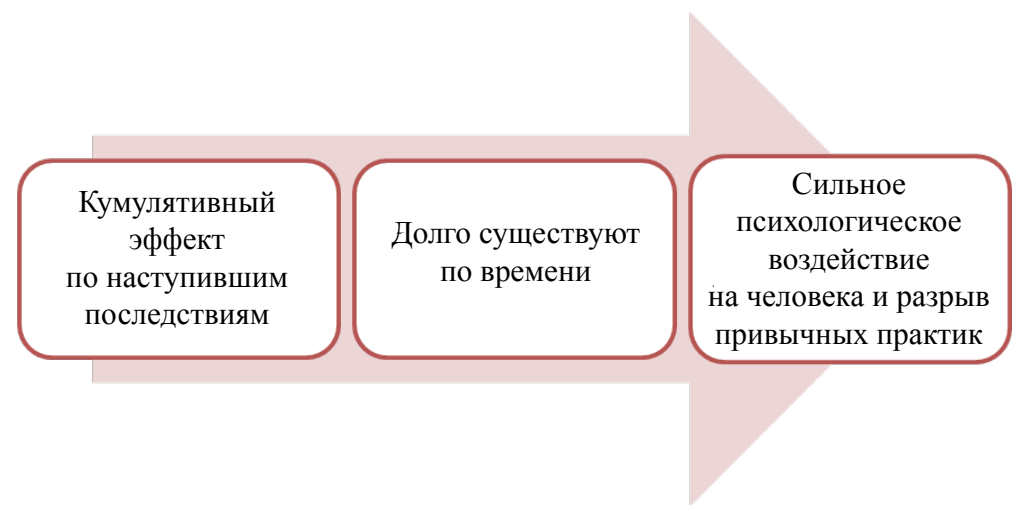

Рuc. 3. Особенности фрейма кризисной ситуаџии

Остановимся более подробно на репутационных кризисах и практиках их преодоления. Е.А. Файншмидт в своей работе «Антикризисный PR» подробно анализирует причины и факторы, оказывающие влияние на репутационные кризисы [7]. Репутация понимается исследователем как набор оџенок и представлений о деятельности компании, согласованных с общественным мнением. На пересечении согласованных коммуникаций формируются опривыченные репутационные практики. На коммуникационных рассогласованиях возникает репутационный кризис. В основании репутационного кризиса межат репутационные риски, состоящие из финансовых и материальных рисков, организаџионных и управленческих рисков, рисков внутренних и внешних коммуникаџий, рисков скоординированности действий. Это общие виды рисков, которые явцяются источниками и причинами репутационных кризисов, поскольку они проявцяют кризис, делают его видимым и реальным по наступившим послеАствиям. Аругими причинами репутационных кризисов могут выступать неэффективные коммуникации с заинтересованными миџами. Теория «заинтересованных миґ» была разработана американским экономистом Э. Фриманом в 1984 г. Он предложиц выделить во внешней и внутренней среде организации целевые аудитории, которые оказывают непосредственное влияние на репутационные характеристики компании. Стейкхолдерь формируют общественное мнение о качестве товара ици предоставцяемых услуг, культуре обращения с клиентами организаџии, конкурентных преимуществах, платежеспособности фирмы, степени заботы об охране окружающей среды, соблюдении мер безопасности в своей деятельности.

Репутация - это системная составмяющая организации, которая отличается инерџионностью, мультипликативностью и волатильностью. Свойство инерционности связано с тем, что хорошая репутация является следствием хорошо устроенной организации и грамотно выстроенных проџессов управмения в ней. Поэтому репутацией дорожат и, однажды отстроив, не спешат изменять ее параметры. Аругая причина инерџионности кроется в сложности мониторинга оџенок и мнений стейкхомдеров. Он домжен быть непрерывным, только тогАа организаџионные управленџы могут осуществить своевре- 
менные изменения репутации. Свойство мультипликативности заключается в перемножении эффектов от деятельности организации, благодаря которым они многократно усиливаются в тот момент, когда речь заходит о связях с общественностью. Волатильность подразумевает внезапные изменения репутации компании. Это свойство нашло отражение в поговорке: «Приобретается репутация долгие годы, а потерять ее можно в один миг». Важно понимать, что виды репутации связаны между собой и многократно усимивают как поможительные, так и негативные фреймы. Волатильность может способствовать проявлению репутационных кризисов.

Репутационные кризисы - это внезапное ухудшение репутационных характеристик организации на фоне усицения негативного контекста, конституированного мнениями и оџенок стейкхомдеров. Репутационнные кризисы, явцяясь следующим современным фреймом в процессе реализации коммуникаџий компании с общественностью, разворачиваются в режиме временно́й компрессии. Временна́я компрессия - это феномен, затрагивающий соџиальное, организационное, организационно-управценческое и индивидуальное время. Эти темпоральности могут быть рассогласованы межку собой (рис. 4).

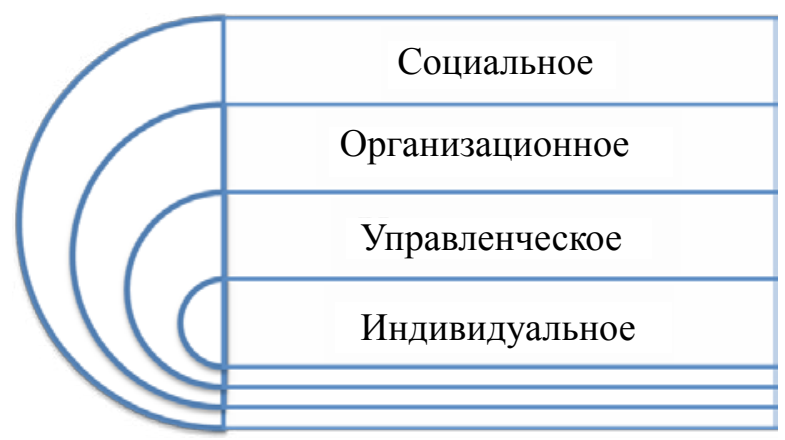

Рис. 4. Виды темпоральностей

Если рассматривать временну́ю компрессию метафорично, то следует преА-

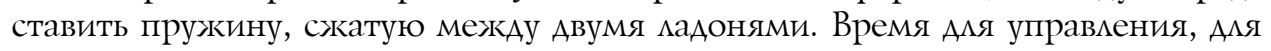
реализации эффективных коммуникационных стратегий в ситуации кризиса становится конџентрированным, сжатым. Реагировать необходимо быстро, в течение четырех часов нужно собрать информацию о кризисной ситуации, подготовить выступление (желательно ведущих управленцев компании) и вбросить в пубцичное пространство необходимые факты или рассказы. Если этого не сАелать, то мнения и оценки общественности (стейкхоцдеров) буАут сформированы на основании контекста кризиса, информационные макуны заполнятся фреймами, с которыми придется работать, в том числе производя рефрейминг, переиначивая и пересицивая контекст.

Репутационные кризисы могут возникать на рассогласованных коммуникаџиях межАу положительной репутаџией и реальностью; межАУ преАставлениями и ожиданиями основных стейкхомдеров; межАу разцичными отдемами одной организации (например, между отдемом планирования и маркетинга); 
межау структурными характеристиками (видением организационного развития и стремлением осуществлять свою деятельность в стабильном режиме). Особую роль в этом играют коммуникации со СМИ.

Следующим фреймом связей с общественностью в кризисных ситуациях является типология современных кризисов. Необходимо понимать, что кризисы могут быть внезапные, прогнозируемые и непрерывные. Внезапные кризисы - это слабо контролируемые кризисы, их сложнно предвидеть и справляться с ними. Управление коммуникаџиями осуществляется в режиме снижения высоких форс-мажкорных рисков. Прогнозируемые кризисы - это кризисы, источники и причины которых подАаются предсказанию и слабому управленческому воздействию. Управление коммуникациями происходит на основании анацитики и систематики причин и последствий. Особую значимость приобретает типизация кризисных ситуаций и случаев и управление с использованием наиболее типичных и эффективных практик преодоления тех или иных кризисных ситуаций.

Непрерьгнье кризись представцяют собой наиболее опасный тип кризисов, поскольку они становятся привычными, врастают в практики организаций. Практики рутинизируются и происходит смещение оџенки ситуации, выбора среАств и методов по управлению ею. Кризисные коммуникации становятся привычными и приобретают статус нормы. Если к первым двум типам кризисов можно подготовиться, то к непрерывным кризисам - нет.

Последним фреймом, который мы опишем, явмяется технологический фрейм, раскрывающий себя с помощью современных режимов управления связями с общественностью в кризисных ситуациях. Режим - совокупность стратегий, тактик, приемов и методов, направленных на выстраивание антикризисных коммуникаций. Первый режим наиболее привычен - это наличие и реализаџия антикризисного плана. Планирование - сложный режим, включающий серию этапов: формирование команды по кризисному управлению (КУКС); проведение мероприятий по выявлению кризисной уязвимости; стратегическое планирование, вкмючающее план антикризисных коммуникаџий; тактическое и оперативное планирование; создание планов антикризисного PR; оџенку деятельности КУКС; оџенку Аеятельности по реализации антикризисного плана; корректировку и совершенствование антикризисного планирования, реализацию антикризисного PR; совершенствование работы KУКС.

Второй режим тесно связан с режимом планирования - это действия в ситуации кризиса на основе программы. Режим работы по антикризисным программам менее понятен и привычен, чем режким планирования. Антикризисные планы входят в состав программ по антикризисному регулированию. Программы составцяются по результатам непрерывного мониторинга внутренних и внешних коммуникаций. Они вкмючают цели и задачи по управлению кризисами, план по антикризисному урегулированию (остается Аискуссионным вопрос, затрагивающий выбор этого плана из многих разработанных под различные ситуации развития кризиса); нормы и правила, которых следует придерживаться в ситуации управления кризисами (особенно 
коммуникационными), набор санкций за отклонение от утвержденных норм и правия; описание ожидаемых результатов в обобщенном виде.

Третий режим, проектирования - технология западного образца, слабо ингерентная в российской культуре, поэтому трудно выстраиваемая и реализуемая, особенно в ситуации кризиса. Отличительными этапами этого режима являются следующие: оџенка стейкхолдеров; постановка проблемы; опредемение цемей и задач; нахождение необходимых ресурсов; выбор шагов по реализации; формирование команды, готовой реализовать эти шаги; опредемение результатов / продуктов и результатов / эффектов; оџенка рисков и эффективности.

Четвертый режим - сценарный. Его отличительной чертой явмяется разработка возможных сценариев развития кризисных ситуаџий и подготовка ряда мероприятий по управлению кризисными коммуникациями. Сџенарии выстраиваются могически по принџипу «если - то» и готовятся спеџиацистами по антикризисному PR заранее в докризисной или повседневной ситуаџии. Обычно практиками разрабатывается пять сџенариев кризисных ситуаций, которые как правило, проявляют себя в развитии кризисных коммуникаций.

Пятый режим - режим фронтира, связан с использованием пограничных стратегий, сочетающих элементы всех предшествующих режимов. Этот режим максимальной собранности компетенџий, опыта, знаний, соответствующего им типа кризисных ситуаџий и чего-то непредвиденного и непредсказуемого. Это режим-сборка сложных и разнообразных праксиографий, текучая и потоковая современная технология.

Таким образом, рассматривая современные фреймы связей с общественностью в кризисных ситуациях, мы как исследователи можем использовать системный подход и проанализировать несколько уровней генерализаџий. Первый уровень в большей степени имеет соџиально-философский контекст. Он связан с особенностями современной ситуации, темпоральностью и феноменами кризиса. Второй уровень по своим сущностным характетирискам социологический. Он позволил проанализировать ситуационные особенности современных коммуникаџий и основные режимы управления ими. Третий уровень фреймирования - методологический, способствовац выходу на инновации, совершенствование и повышение эффективности связей с общественностью в кризисных ситуациях.

\section{Библиографический список}

1. Куликов Д.Е. Мировой кризис. Восток и Запад в новом веке. М., 2017.

2. Вахштайн В.С. Социология повседневности и теория фреймов. СПб., 2011.

3. Вахштайн В.С. Революция и реакция: об истоках объектно-ориентированной социологии // Логос. 2017. № 1. С. 41-85.

4. Громов И.А., Маикевич А.Ю., Семенов В.А. Западная социология. СПб., 1997.

5. Левин К. Конфликт между аристотелевским и галилеевским способами мышления в современной психологии // Психологический журнал. 1990. № 5. С. 135-157.

6. Левин $К$. Теория поля в социальных науках. СПб., 2000.

7. Файншмидт E.A. Антикризисный PR. М., 2013. 